\title{
Evaluation of SME (Small Medium Enterprise) production system with discrete system simulation method
}

\author{
Reno Dias Anggara Purba*, M Iqbal Sabit, and Joko Sulistio \\ Department of Industrial Engineering, Faculty of Industrial Technology, Indonesia
}

\begin{abstract}
Like manufacturing companies that have flowshop production lines, SME facing the amount of flow time and makespan. Unfulfilled production targets, buildup on some machines that result in other machines being idle, increasing waiting times across multiple machines, and poor performance of workers are a series of problems facing SME. This article uses a discrete system simulation method to analyze and evaluate SME production lines to improve performance. Simulation is an appropriate tool used when experiments are needed in order to find the best response from system components. From the results of modeling and simulation done found the root of the problem is due to accumulation that occurs in one machine and the lack of utility of the operator in producing bags. So do the experimental design with 3 scenarios on the system that have been modeled and obtained some solutions that can be offered to solve the problem. Furthermore, after the alternative selection is obtained the best scenario based on the alternative selection test is the scenario 3 by adding 2 new machines and 1 new operator on the production line obtained a significant output increase compared to other scenarios of approximately $30 \%$. While the best scenario based on the minimum cost is the scenario 2 by adding 2 new operators obtained output that is not much different than the scenario3. However, it has not been able to solve a series of problems facing SME. Therefore, the results of this study to solve a series of problems faced by SME is to add facilities in the production line of 2 new machines and 1 operator (scenario3).
\end{abstract}

\section{Introduction}

Flowshop scheduling is a continuous movement of units through a series of work stations arranged by product. The arrangement of a flowshop production process can be applied appropriately to products with a stable design and produced in large quantities (product volumes), so special purpose investments that can be quickly returned. Flow Shop, a production system that arranges machines based on the order of processing (routing) products, so often referred to as the product layout (product layout) (Baker, 1974). In general, scheduling is a process in production planning and control that is used to plan production and allocation of resources at a given time with respect to the capacity of existing resources.

Scheduling in outline based on the sequence of production process is divided into 2 kinds (Masruroh, 2008). First, Job Shop is the flow pattern of $N$ job through $\mathrm{M}$ machine with any flow pattern and job sorting process for irregular product trajectory. Scheduling on the production process of job shop one of its characteristics is the form of job shop layout is usually classified from equipment that has similar functionality in an area (Badworth, 1987). Second, Flow Shop is the process of determining the sequence of jobs that have the same product trajectory. Basically there are several kinds of flow shop patterns, among others: (a) Pure Flow Shop, Flow shop which has the same production line for all tasks. The machine is structured according to the existing process flow where a job is required to undergo a one-time process for each condition. (B) General Flow Shop has a different flow pattern, where the General Flow Shop flow pattern has characteristics: The flow of the process always shows the direction to the right, the sequence of operations may not be sequential (Farouq, 2013).

Problems or constraints that SME often face are production problems. SME are often unable to meet market demand because they can not meet production targets. This research uses a SME engaged in handicrafts in Yogyakkarta. Based on the interviews, it is known that SME have a minimum market demand of 55 units per day. However, the production output per day is less than 40 units. Then, the manufacturing process time for one product. Moreover, less optimal use of existing machines that result in utility of workers decreased.

This is because 2 of 19 machines owned damaged. While the number of workers owned 17 people. Thus each operator is assigned on 1 machine. In addition, the operator also duty to deliver flowitem from one process to another process. Such conditions lead to increased waiting time for the operator to deliver the flowitem from one of the machines. Thus, the impact is the occurrence of blocked or bottleneck on some machines. Therefore, the utility of the operator becomes reduced in processing the flowitem. This study aims to improve

\footnotetext{
* Corresponding author: 15522226@students.uii.ac.id
} 
work performance and optimization of production factors from the company by analyzing the behavior of production systems using simulation methods and to evaluate in order to achieve the purpose of this research.

Simulation is a technique to mimic the operations or processes that occur in a system with the help of computer devices and is based on certain assumptions so that the system can be studied scientifically. In the computer simulation used to study the system numerically, then doing data collection to make statistical estimation to obtain the original characteristics of the system. Simulation is the right tool to use especially if required to conduct experiments in order to find the best comments from system components. This is because it is very expensive and takes a long time if the experiment is tried in real terms. By doing a simulation study then in a short time can be determined the right decision and with a cost that is not too large because everything is done with the computer. The simulation approach begins with the development of a real system model. The model should be able to show how the various components in the system interact so that it really describes the behavior of the system. Once the model is created then the model is transformed into a computer program allowing it to be simulated (Law \& Kelton, 1991).

\section{Method}

This research uses qualitative description method. The data used are primary data obtained from observation and interview. The first stage in this study is to observe in a predetermined location. Then do the data collection needed for modeling. The data required is the data processing time of each machine and the flow of production process. Next, done data processing and modeling using software flexsim 6 . After the model is made, then the simulation. Simulation output data is used to perform validation to ensure the credibility of the model, if the output data of the simulation results are not in accordance with the output data in the real system then do the data collection again. While if appropriate then can be done analysis on the model. Furthermore, an experimental design was created to solve the problem at hand. Next, make the best alternative selection by doing anova test followed by bonferroni test to see the significant difference of each scenario. The final stage of this research is to analyze the cost of each scenario so that some suitable solutions are obtained.

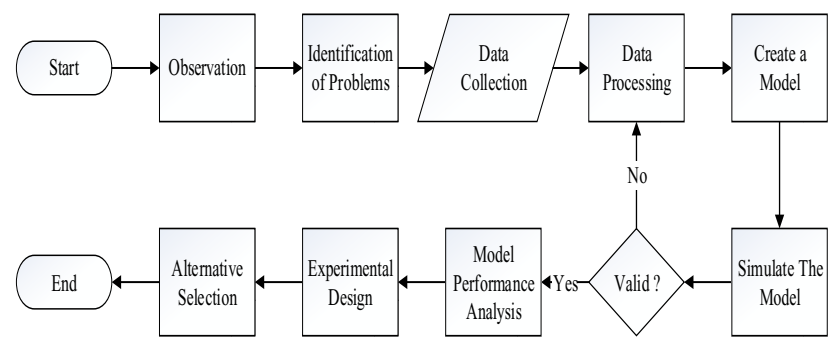

Fig. 1. Scheme of research methodology

\subsection{Object of Research}

The production process in SME Zanoproduction has 7 stages of the process: (1) pattern making and cutting, (2) tailoring the front, (3) rear and side of the bag, (4) fitting bag handles, (5) zipper installation, 6) inspection, and (7) packing. The sequence of production processes for all jobs is the same through the sequence from start to finish with the same groove and 1 machine has only 1 function (flowshop).

\section{Result}

Once the model is built, then enhanced its credibility by validating. The following historical data is obtained from obervation for 30 days, while for the simulation result data obtained from the simulation run of 30 replication. This validation process uses a chi-square test to test the results of the simulation model having a match with the observed real system.

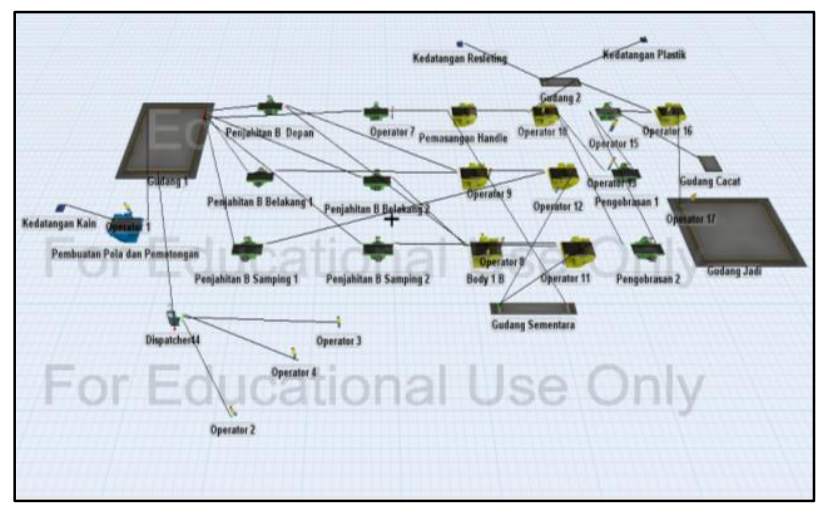

Fig. 2. Model Built in Flexsim

Table 1. Historical Output Data and Simulation

\begin{tabular}{cccccccc}
\hline \multicolumn{3}{c}{ Historical } & \multicolumn{5}{c}{ Simulation } \\
\hline \multirow{2}{*}{ Data to- } & & $\begin{array}{c}\text { Data } \\
\text { to- }\end{array}$ & $\begin{array}{c}\text { Data } \\
\text { to- }\end{array}$ & $\begin{array}{c}\text { Data } \\
\text { to- }\end{array}$ \\
\hline $\mathbf{1}$ & 30 & $\mathbf{1 6}$ & 37 & $\mathbf{1}$ & 36 & $\mathbf{1 6}$ & 31 \\
$\mathbf{2}$ & 38 & $\mathbf{1 7}$ & 37 & $\mathbf{2}$ & 39 & $\mathbf{1 7}$ & 32 \\
$\mathbf{3}$ & 37 & $\mathbf{1 8}$ & 35 & $\mathbf{3}$ & 37 & $\mathbf{1 8}$ & 40 \\
$\mathbf{4}$ & 38 & $\mathbf{1 9}$ & 30 & $\mathbf{4}$ & 37 & $\mathbf{1 9}$ & 37 \\
$\mathbf{5}$ & 37 & $\mathbf{2 0}$ & 38 & $\mathbf{5}$ & 31 & $\mathbf{2 0}$ & 30 \\
$\mathbf{6}$ & 35 & $\mathbf{2 1}$ & 35 & $\mathbf{6}$ & 30 & $\mathbf{2 1}$ & 37 \\
$\mathbf{7}$ & 36 & $\mathbf{2 2}$ & 36 & $\mathbf{7}$ & 39 & $\mathbf{2 2}$ & 37 \\
$\mathbf{8}$ & 37 & $\mathbf{2 3}$ & 35 & $\mathbf{8}$ & 33 & $\mathbf{2 3}$ & 41 \\
$\mathbf{9}$ & 39 & $\mathbf{2 4}$ & 39 & $\mathbf{9}$ & 37 & $\mathbf{2 4}$ & 30 \\
$\mathbf{1 0}$ & 38 & $\mathbf{2 5}$ & 38 & $\mathbf{1 0}$ & 39 & $\mathbf{2 5}$ & 35 \\
$\mathbf{1 1}$ & 37 & $\mathbf{2 6}$ & 30 & $\mathbf{1 1}$ & 36 & $\mathbf{2 6}$ & 34 \\
$\mathbf{1 2}$ & 38 & $\mathbf{2 7}$ & 39 & $\mathbf{1 2}$ & 30 & $\mathbf{2 7}$ & 37 \\
$\mathbf{1 3}$ & 37 & $\mathbf{2 8}$ & 37 & $\mathbf{1 3}$ & 34 & $\mathbf{2 8}$ & 38 \\
$\mathbf{1 4}$ & 39 & $\mathbf{2 9}$ & 30 & $\mathbf{1 4}$ & 35 & $\mathbf{2 9}$ & 31 \\
$\mathbf{1 5}$ & 36 & $\mathbf{3 0}$ & 38 & $\mathbf{1 5}$ & 32 & $\mathbf{3 0}$ & 39 \\
\hline
\end{tabular}

H0: $\mu 1=\mu 2$, The average output of the real system is the same as the average output of the Simulation model. 
$\mathrm{H} 1: \mu 1 \neq \mu 2$, The average output of a real system is not the same as the average output of the Simulation model.

The model has been built, then validated the output by applying the two-equality test, the two-variance equation test, and the chi-square. After the calculation of statistical tests then found that the value of $\mathrm{Z}$ arithmetic obtained for 0.455830058 . According to the test criteria Since $-\mathrm{Z} 0.025<\mathrm{Z}$ arithmetic $<\mathrm{Z} 0.025$, ie: $-1.96<\mathrm{Z}$ count $<1.96$. Then H0 is accepted which means the average output of the real system corresponds to the average output of the simulation model. After the calculation of statistical tests looking for $\mathrm{F}$ arithmetic, then found that the value of $F$ arithmetic of 1.7358 . According to the test criteria because $0.975<\mathrm{F}$ arithmetic < F 0.025 tab ie: $0.475965<1.7358<$ 2.100996. Then H0 is accepted which means the average output of the real system is equal to the average output of the simulation model.

From the test results obtained chi square calculated value is 37.74 , whereas with $\alpha$ : 0.05 obtained chi-square table is 42.56 . Thus, the observed frequency of the simulation model is consistent with the theoretical frequencies of the actual system. After testing, the model is said to be valid and has met the test. So the model can be said to have sufficient credibility, as well as built models can represent the real system well. So the results of this model can be used to improve the performance and problem solving faced.

\section{Discussion}

Table 2. Simulation Report

\begin{tabular}{cccc}
\hline \multicolumn{4}{c}{ Model Stop Time : 28800 (Second) } \\
\hline Object & Class & Idle & Blocked \\
Hemming 1 & Processor & $78.03 \%$ & $0.94 \%$ \\
Hemming 2 & Processor & $74.21 \%$ & $0.59 \%$ \\
Sewing B & Processor & $7.25 \%$ & $67.36 \%$ \\
Side 1 & & & \\
Sewing B & Processor & $0.33 \%$ & $76.00 \%$ \\
Backward 1 & & & \\
Sewing B & Processor & $0.25 \%$ & $80.05 \%$ \\
Backward 2 & & & \\
Object & Class & Idle & Utilize \\
Operator 15 & Operator & $92.20 \%$ & $3.44 \%$ \\
Operator 16 & Operator & $92.81 \%$ & $4.37 \%$ \\
\hline
\end{tabular}

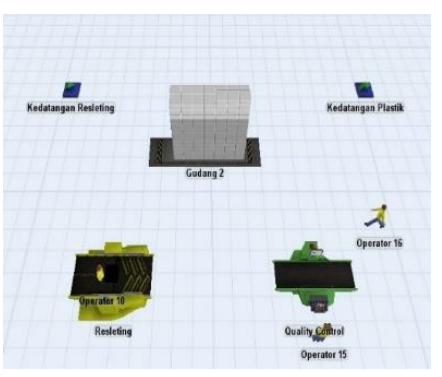

Fig. 3. Problem state

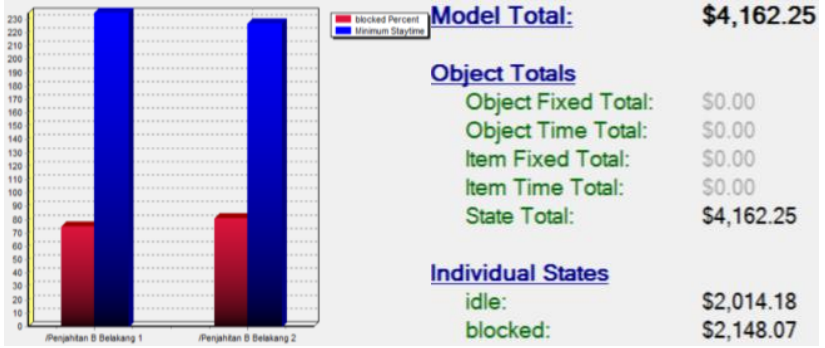

Fig. 4. Blocked, staytime object comparison, financial report

From Figure 3 shows the visual observations after the simulation ended with a simulation time of 28800 seconds. Simulation results show that there are still semi-finished goods or flowitem on some machines and in semi-finished warehouse. In addition, there are some operators who are not in the workplace, one of which Operator16. It appears blocked due to the accumulation that occurs on some machines that cause the production process on the machine after it is hampered and there idle. This is due to the flowitem being retained in the initial process in the Tailoring machine. So a little flowitem that goes into the final process in the Hemming machine, Quality Control, and Packing. In addition, idle occurs in some operators who work in the final stages of production due to the delay flowitem to be produced and cause the addition of waiting time. As a result of buildup on some machines, causing blocked occurrence in many engines. Blocked machines are: Sewing B Side 1, Sewing B Backward 1, and Sewing B Backward 2. In addition, increased waiting time and idle causes in some machines and operators. Machines that experience an increase in idle are: Hemming1 and Hemming2 engines. While the operators who experience an increase in idle are: Operator 15 and Operator 16 which served on Quality Control and Packing machine. In addition, the greater the idle value of the operator causes the utilize value of the operator in processing the increased flowitem. So automatically makespan and flowtime in the bag production process is also enlarged thus affecting the quantity of the final output produced. Then from figure 4 can be seen the comparison between the staytime with the blocked that occurs on the machine Sewing Backward B 1 and the Hemming 1. Where there is increased waiting time and blocked in both machines. Furthermore, from figure 5 the amount of blocked and idle values on the Sewing Backward B 1 and Hemming machine is converted to a cost of approximately $\$$ $4000 /$ day. The fee is only for 2 machines as a sample. Because the cost of conversion results is large, SME experience losses. So it is necessary to make improvements on the SME production line.

\subsection{Design of Experiment}

In this research, the experiments are 3 scenarios. Scenario 1 by adding 2 new machines to complete blocked on 3 machine that is: (1) Sewing B Side 1 (2) Sewing B Backward 1 (3) Sewing Backward B 2. Then to lower idle on 2 machine that is: (1) Hemming 1 (2) Hemming 2 and lower idle of 2 operators are: (1) 
Operator 15 (2) Operator 16. Scenario 2 by adding 2 new operators to improve utilize of 2 operators: (1) Operator 15 (2) Operator 16 Scenario 3 by adding 2 machines and 1 new operator to solve a series of problems facing SME.

\section{Gudang Jadi}

Mean ( $90 \%$ Confidence) Sample Standard Deviation Min Max

Scenario $142.96<44.83<46.7 \quad 6.02 \quad 32 \quad 55$

Scenario $243.17<45.07<46.96 \quad 6.12 \quad 34 \quad 57$

Scenario $342.52<44.57<46.61 \quad 6.6 \quad 33 \quad 59$

Fig. 5. The improvement of output's number

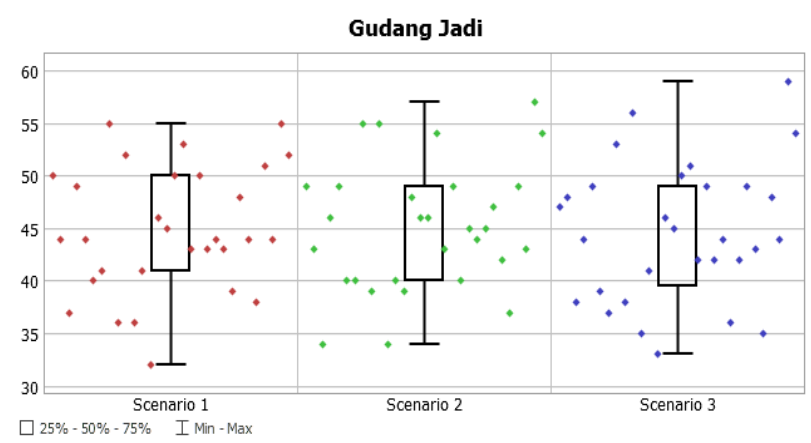

Fig. 6. The improvement of output's number

\subsection{Alternative Selection}

In the test results anova value $\mathrm{F}$ count $>\mathrm{F}$ table, ie $3.382155>3.101296$ then H0 rejected and Ha accepted, which means there is difference in output output scenario1, scenario2 and scenario3. This distinction is a requirement in the Bonfferoni test that will be a further step in alternative selection. Furthermore, the selection of the best alternative is selected by testing the bonffernoni with the following hypothesis:

Ho : There is no significant mean difference in the output that is influenced between the skenario

$\mathrm{Ha}$ : There is a significant mean difference in the output that is influenced between the skenario

Testing Criteria:

Ho rejected, if $\mathrm{P}(\mathrm{T}<=\mathrm{t})$ two-tail $<\alpha / \mathrm{n}$

Ho accepted, jika $\mathrm{P}(\mathrm{T}<=\mathrm{t})$ two-tail $>\alpha / \mathrm{n}$

(1) In the bonferroni test it is found that the value of $P$ $(\mathrm{T}<=\mathrm{t})$ one-tail $(0.464635525)>$ alfa $/ \mathrm{n}$ $(0.016666667)$ then $\mathrm{H} 0$ is accepted which means there is no significant mean difference between scenario output1 and scenario2.

(2) In the bonferroni test it is found that the value of $\mathrm{P}$ $(\mathrm{T}<=\mathrm{t})$ one-tail $(0.042712284)>$ alpha/n $(0.016666667)$ then $\mathrm{H} 0$ is accepted which means there is no significant mean difference between scenario 2 and scenario 3.

(3) In the bonferroni test it is found that the value of $\mathrm{P}$ $(\mathrm{T}<=\mathrm{t})$ one-tail $(0.008349887)<\mathrm{alfa} / \mathrm{n}$ $(0.016666667)$ then $\mathrm{HO}$ is rejected and $\mathrm{Ha}$ is rejected which means there is a significant mean difference between scenario1 and scenario 3 .

\subsection{Alternative Cost Analisys}

Table 3. Simulation Report

\begin{tabular}{cccc} 
No & Facility & Quantity & Cost \\
\hline 1 & Sewing & 1 & Rp. 2.000 .000 \\
& Machine & & \\
2 & Operator & 1 & Rp. 1.000 .000 \\
\hline
\end{tabular}

From the result of alternative selection test above can be seen that there is no significant average difference between the output of scenariol with the output of scenario2. This means both alternatives are just as good or nothing better. The same can be seen by comparing the mean and variance of the two alternatives that have almost the same value. Then because scenario 2 is no better than scenariol then scenario 2 can not be selected if it refers to result of alternative selection test. Then from the result of alternative selection test above can be seen that there is no significant average difference between the output of scenario2 with the output of scenario3. This means scenarios and scenarios 3 are equally good or there is nothing better between them. However, when viewed from the mean and variance between the two alternatives having a mean difference of 3 and the variance difference of 15 , this indicates that there is a considerable difference in the difference to choose the best alternative. Then from the alternative selection test results above can be seen there is a significant average difference between the output scenario1 with the output scenario3. This means the two alternatives are not as good or scenario3 is better than scenario1. The same can be seen by comparing the mean and variance of the two alternatives having the difference for the mean of 4 and the variance of 19 .

Then because scenario 3 is better than scenario 1 then scenario3 can be chosen as the best alternative when referring to alternative selection test result. Scenario 3 is done by adding 1 operator, adding 1 machine Body $1 \mathrm{~B}$ and 1 machine Body $2 \mathrm{~B}$. This will surely increase the cost incurred by company to hire 1 operator, and to buy 2 new machine, then scenario1 that is done addition of 1 machine Body $1 \mathrm{~B}$ and 1 machine Body $2 \mathrm{~B}$, while scenario 2 is done by adding 2 operators. This of course will increase the cost incurred by the company to pay 2 . If it is assumed the cost to pay 1 operator of $\mathrm{Rp}$. $1,000,000$ and the cost to buy 1 new machine is $\mathrm{Rp}$. $2,000,000$ then the total cost incurred for scenario 3 is Rp. 5,000,000, then the total cost incurred for scenariol is Rp. 4,000,000, and the total cost incurred for scenario2 is Rp. 2,000,000. When compared in terms of cost, the scenario 2 can be selected as the best alternative because it costs a minimum of about half of the scenario3 and has an average output that is not much different. However, it has not been able to solve a series of problems facing SME. Therefore, to solve a series of problems facing SME it is advisable to choose scenarios 3 even with slightly larger costs compared to scenarios 2 .

Previous research conducted by (Ramírez-Granados, Hernández, \& Lyons, 2014). In Their journal entitled "A Discrete-event Simulation Model for Supporting the First-tier Supplier Decision-Making in a UK's 
Automotive Industry" has a problem that the company can not meet production targets. By using discrete system simulation modeling and simulation. From 5 scenarios that have been made then got the best scenario is by adding 3 new operators in different production lines obtained output that can meet the company's production target and greater than other scenario. Various similarities with this research that has the same problem that the company can not meet production targets. The method used the same, namely by using a discrete system simulation. Then both do the verification and validation of the model built. Then the difference is the software used to build different models. In the previous study did not use alternative selection test to determine the best scenario by considering the significant difference of output between scenarios. Furthermore, do not use the cost analysis of the scenario that has been created to analyze the scenario that has the least cost with maximum output. Therefore, this study is better than previous research.

\section{Conclusion}

The performance of SME production system is less than optimal, this can be seen from the many flowitem that still accumulate in the system when the simulation ended. This is due to the time factor of the production process and the capacity it processes. In addition, the reduced utility of operators in processing flowitem causes SME unable to meet production targets. Then the best scenario based on alternative selection test result is scenario3 that is adding 2 new machine and 1 new operator in production line obtained significant increase of output compared to other scenario about $30 \%$. While the best scenario based on the minimum cost is the scenario 2 that is adding 2 new operators obtained output that is not much different than the scenario3. However, it has not been able to solve a series of problems facing SME. Therefore, the result of this research to solve a series of problems faced by SME is by adding facilities in the production line ie 2 new machines and 1 new operator (scenario3).

\section{References}

1. Badworth, D. Integrated Production Control System. New York: John Wiley \& Sons, Inc. . (1987)

2. Baker, K. Introduction to Sequencing and Scheduling. Canada: John Wiley \& Sons, Inc. (1974).

3. Farouq, E. Simulasi Aturan Johnson Untuk Penjadwalan Produksi Flowshop di Perusahaan Furniture. Malang: Jurusan Ilmu Komputer Program Studi Teknologi Informasi dan Ilmu Komputer Universitas Brawijaya. (2013).

4. Law, A. M., \& Kelton, W. D. (1991). Simulation Modeling \& Analysis, second edition. McGraw-Hill: International. (1991).

5. Masruroh, N. Analisa Penjadwalan Produksi dengan Menggunakan Metode Campbell Dudeck Smith, Palmer dan Dannenbring di PT. Loka Refraktoris Surabaya. Surabaya: Jurusan Teknik Industri Fakultas Teknik Industri Universitas Veteran UPN Surabaya. (2008).

6. Ramírez-Granados, M., Hernández, J., \& Lyons, A. A Discrete-event Simulation Model for Supporting the First-tier Supplier Decision-Making in a UK's Automotive Industry. Journal of Applied Research and Technology. (2014). 